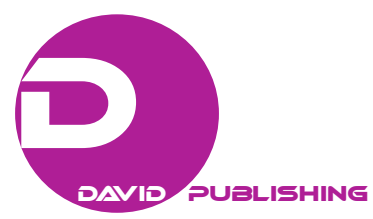

\title{
“Greasing the Skids”: Interdisciplinary Rhetoric and Mindblindness
}

\author{
John Marinan \\ Georgia Gwinnett College, Lawrenceville, Georgia
}

\begin{abstract}
The idea of mindblindness reaching outside of neuroscience is an important one. It is significant because there is concern in all quarters about the prevalence and meaning of autism diagnoses. Secondly, mindblindness rhetoric reflects the kinds of rhetorical devices scholars use to analyze this theory. Finally, mindblindness is a fertile ground for research collaboration between neuroscientists, social scientists and humanities scholars as it skirts the boundaries of disciplinarity. What about mindblindness theory makes it an interdisciplinary phenomenon, complete with interdisciplinary collaborations and mutual knowledge-seeking? I argue in this paper that specific forms of rhetoric "grease the skids," meaning that they can be construed flexibly in both the neuroscientific language and the "other-discipline" language. Because of the flexibility of these rhetorical conveyances, interdisciplinary collaboration has exploded around mindblindness dialogue, despite the traditional differences in disciplinary methodology.
\end{abstract}

Keywords: theory of mind, mindblindness, interdisciplinarity, autism spectrum disorder

\section{Introduction}

In this paper, I seek to address the issue of mindblindness in autism research. Mindblindness is a theory in neuroscience that attempts to state that autistics do not have the ability to read mental states of others. I examine this theory and try to determine if mindblindness has an interdisciplinary connection outside of neuroscience. The argument under consideration is whether or not autism has disciplinary outcomes that go beyond just disability studies. I conclude that indeed they do.

\section{Mindblindness Theory}

The addition of Asperger Syndrome in the DSM-IV (1994) sparked debate about the classification, diagnosis, and culture of mental illness because it expanded the numbers of the autistic population drastically. Along with the advent of the Asperger syndrome diagnosis came a corresponding increase in theorizing about its causes. One of the most significant of these theories of autism over the last twenty years has been mindblindness theory (Baron-Cohen 200). Mindblindness theory states that autistic children fail to read minds and intentions of others in "false belief" tests (Baron-Cohen, 201). ${ }^{1}$

Mindblindness sprang from the discipline of neuroscience but has resisted its place there. Baron-Cohen's attempts to popularize mindblindness for public consumption through a popular book launched it into the

\footnotetext{
John Marinan, Assistant Professor, Georgia Gwinnett College.

${ }^{1}$ In short, scientists provide a series of scenarios that are true, and another that is false. They conclude that autistics cannot discern the false from the true scenarios, thus indicating an autistic deficit in theory of mind.
} 
public lexicon. Mindblindness took on rhetorical as well as scientific significance soon after the publication of Baron-Cohen's early work on the subject.

Not surprisingly, other disciplinary scholars have been interested in mindblindness theory because of its social ramifications. Commentators and scholars in psychology (Gray), philosophy and religion (Aminoff), and cultural studies (Bombaci) have also weighed on mindblindness, reflecting on it as a metaphor for some greater human communication issue. They take neuroscientific research and comment on the theory in their own disciplines.

The idea of mindblindness reaching outside of neuroscience is an important one. It is significant because there is concern in all quarters about the prevalence and meaning of autism diagnoses. Secondly, mindblindness rhetoric reflects the kinds of rhetorical devices scholars use to analyze this theory. Finally, mindblindness is a fertile ground for research collaboration between neuroscientists, social scientists and humanities scholars as it skirts the boundaries of disciplinarity.

\section{Mindblindness and Interdisciplinarity}

Interdisciplinarity is the movement towards dialogue and co-creation of knowledge domains in multiple fields (Augsburg, 2006, p. 10). There is already healthy interdisciplinary participation in the field of autism studies. Porayska-Pomsta et al. utilize an interdisciplinary approach for designing multi-modal technology to assist students with ASD. They utilize the ECHOES Project, an interdisciplinary, multi-partner project whose goal is to develop a rich technology environment to support young typically developing (TD) children and children with ASDs aged between 5 and 7, in exploring and acquiring social interaction skills (118). ECHOES' methodology and the learning environment rely crucially on multi-disciplinary expertise including developmental psychology, visual arts, human-computer interaction, artificial intelligence, education, and several other cognate disciplines (2011, p. 118).

Milton and Moon have also spoken about the normalization of the psycho-emotional disablement of autistic people. They utilize psychological theories to argue that a "normalizing agenda" has led to the silencing of the autistic voice in knowledge production and community awareness. They challenge the work of Ivor Lovaas and his behavioral model of resuscitation of the autistic child.

Even writers have broached the discussion. Francisco Stork's Marcelo in the Real World, Emily Franklin and Brendan Halpin's The Half-Life of Planets, Lisa Genova's Love Anthony, and Elizabeth Moon's Speed of Dark are just a few examples of recent popular authors, in various genres, bringing the subject of autism and mindblindness to light.

But what about mindblindness theory makes it an interdisciplinary phenomenon, complete with interdisciplinary collaborations and mutual knowledge-seeking? I argue in this paper that specific forms of rhetoric "grease the skids," meaning that they can be construed flexibly in both the neuroscientific language and the "other-discipline” language. Because of the flexibility of these rhetorical conveyances, interdisciplinary collaboration has exploded around mindblindness dialogue, despite the traditional differences in disciplinary methodology.

To ascertain interdisciplinarity in mindblindness discourse, it is important to see it in its various rhetorical manifestations in other fields. I briefly examine Baron-Cohen's original work, then trace three principal strands of mindblindness discussion to that original discussion. First, there is dialogue within neuroscience. These neuroscientists promote the idea of embodied simulation through the idea of mimesis. Secondly, psychologists 
argue against the "intellectualist" and empiricist limitations of Theory of Mind. They argue about the idea of the alien metaphor. Finally, humanities scholars argue how mindblindness research makes a case for the ways in which autistics read fiction. They employ postcolonial literary theory and compare the autistic to subaltern man. All of these dialogues utilize rhetorical language that possesses dual meanings for both neuroscience and that particular field, thus making interdisciplinary collaboration uniquely possible.

Simon Baron-Cohen's Mindblindness: An Essay on Autism and Theory of Mind, is the principal work in the field from which all commentaries flow. In it, he argues that autistic individuals cannot read minds like neurotypicals (they cannot interpret emotional intentions from the faces of others). Baron-Cohen takes what is called a multi-modular approach to cognitive analysis of the brain. He believes these modules are separate computers with different functions such as "short term memory," “attention," and “induction” (1995, p. xiv). In other words, not only is our mind a computer but there are regions of the brain that are separate computers. Vital to his description is the metaphorical nature of mind as computer.

Theory of Mind is one such explanation of a module that speaks of agents, beliefs, and desires and links them to the language of the eyes (Baron-Cohen, 1995, pp. xiv-xv). In other words, people speak with their eyes, which is also highly metaphorical. Baron-Cohen's argument is that in autism, the T.O.M.M. is broken, and these subjects cannot converse through eye contact because they have no neural architecture that "reads" these messages from others. In a highly descriptive way, autistics see without seeing.

Baron-Cohen distinguishes the normal brain from the abnormal brain of the autistic. He says that "cognitive scientists were awakened by a series of encounters with alien minds, whose starkly contrasting designs and surprising incapacities drew attention to previously overlooked natural human competences and to the computational problems they routinely solve” (Baron-Cohen, 1995, p. viii). In other words, normal brains work seamlessly in these problem-solving actions and only through broken T.O.M.M. do we realize that autistic brains do not work the same way.

\section{Opposition to Mindblindness: Embodied Simulation}

Mindblindness dialogue originated within neuroscience. Some neuroscientists have difficulty with the theory and use empirical science to support their positions, but the interesting factor is that their research is based on the idea of mimesis, which is a deeply rhetorical idea. Embodied simulation theorists approach the idea of mindblindness from a different angle. Their research idea is simple; we copy the people we see. This concept, called mimesis (imitation), has a biological bent. Catherine Kerr distinguishes Theory of Mind perspective from embodied simulation perspective:

Theory of Mind investigators assert that humans take in the belief states and intentions of another person by cognitively holding "a theory of mind" that posits the other person's mental contents as individuated and separate. ES theorists hypothesize that we make inferences about the mental states of another person by directly and automatically perceiving the other's state of mind through a subtle simulation of his or her actions, emotions, and goals in the "mirror neuron system" in the brain. (Kerr, 2008, p. 206)

Kerr cites Baron-Cohen's main contention that "what is referred to as a 'theory of mind,' is a uniquely human cognitive capacity that comes online after earlier language, motor, and perceptual abilities are established” (2008, p. 207). Kerr shows that ES theorists argue that we make inferences about the mental states of others by directly experiencing their state of mind through a subtle simulation of their actions and emotions in our own sensori-motor systems. This immediate perceptual experience allows us to derive an account of the 
thoughts and intentions of the other person (2008, pp. 207-208).

The essential difference is that when compared, the opposition between Theory of Mind and simulation appears to be a stark contest between a theory of intersubjectivity as cognitive and mental versus a theory of intersubjectivity as perceptual and embodied (Kerr, 2008, p. 208). To put it more clearly, in embodied simulation, the perception is immediate and does not require a "theory," like Theory of Mind does. It does not have to be thought about. This would seem to link more closely with the automaticity of seamless "mentalizing" that Baron-Cohen talked about in his own research.

Embodied simulation rejects brain modularity, the idea that there are perceptual parts of the brain that are separate from the thinking and mental states part of the brain (Rohricht et al., 2014). The research embodied simulation theorists use is on mirror neurons of monkeys, where they discovered that monkeys embody the actions of others (they are able to do the right thing in the right situation due to imitation). Since monkeys are non-speech oriented, the argument goes that they can ascribe mental states through perception and action, two "lower" brain processes. If this is the case, then ascribing mental states would not be a mental abstraction as Baron-Cohen says but rather more like a reflex tied to neurons in the brain.

Kerr's ideas offer a different perspective to Baron-Cohen's Theory of Mind. Kerr utilizes the mindblindness research to bring her own theories to bear on the subject of autism. Kerr has invoked the rhetorical idea of imitation while using neuroscience research on mental processes. Imitation is not new to rhetorical studies, nor is it a foreign concept in science either. In ancient Greece, mimesis (invention) was an idea that governed the creation of works of art, in particular, with correspondence to the physical world understood as a model for beauty, truth, and the good. Plato contrasted mimesis, or imitation, with diegesis, or narrative. After Plato, the meaning of mimesis eventually shifted toward a specifically literary function in ancient Greek society, and its use has changed and been reinterpreted many times since then. Kerr's view, a more physical concept of autism, looks at imitation as a physical/biological/genetic process. It takes away the mentalizing nature of autistic behavior while replacing it with the embodied approach. Kerr's argument echoes embodied simulation scholars' ideas that autistics don't necessarily have deficits in specific areas of the brain but rather in areas of imitation. They have trouble "perspective-taking," or seeing themselves in "another's shoes." This opens up all sorts of issues with autistics as audience members, fiction readers, and the like. Conson et al. argue that in recent tests, autistic children had difficulty "perspective-taking," which in the case of the experiments means transporting themselves into the minds of other people (2015, p. 115).

In this way, Kerr's research represents a "stepping-outside” of the boundaries of neuroscience. There is much support for this kind of interdisciplinary work. By using imitation, Kerr's research on embodiment extends to interdisciplinary aspects utilized in other fields and disciplines. Kerr's work with embodied simulation is based in imitation, which can be seen from the biological perspective as well as the rhetorical perspective. Imitation has a long history in rhetorical studies. For students, the intention of imitation was to provide a kind of literary and rhetorical apprenticeship by which the best modes of expression from the best models could be appropriated in a regulated, graduated fashion. Imitation was the bridge between one's reading and writing (or speaking). It also represented the pragmatic arena in which issues of arrangement and style were considered simultaneously, not separately as they sometimes appear to be in the abstraction of a curricular outline. As a method of composition, imitation is closely related to the principles and practices of amplification and variation. Students moved from close imitations of their models to looser sorts, using these models increasingly as starting points for longer, more involved compositions of their own making. 
What does this mean for interdisciplinary dialogue? Imitation is understood in two ways: through biological "copying" and through the imitation of ancient rhetorical tradition. There is a meeting point by which the discipline of neuroscience can talk about differing theories of mindblindness and embodied simulation. The rhetorical trope of mimesis is the means by which this argumentation has taken place in neuroscience.

\section{Social Science Critiques of Mindblindness}

Other scholars from the social sciences take issue with the success (ubiquity) of the mindblindness metaphor. Educational psychologists Anne McGuire and Rod Michalko argue that rather than treating autism as a puzzle that must be solved, we treat autism as a teacher and thus as having something valuable to contribute toward an understanding of the inherent partiality and uncertainty of human communication and collective life (2011, p. 162). Their argument is that Theory of Mind problematizes the very humanity of the autistic person because of its emphasis on deficit metaphors. Their principal objection to the Theory of Mind is that it assumes that somehow the autistic is broken:

Autism, as a thing, is understood by biomedicine as an empirical object and thus as knowable through the scientific enterprise of gathering data and evidence, i.e. the pieces of the puzzle. Essentially, biomedicine treats autism as a condition found in some individuals and as a condition that generates negative effects. Autism becomes an individual, medical problem to which there must be a collective, medical solution. There is nothing social about this conception of autism except positing its negative effects on an individual’s social life. (McGuire \& Michalko, 2011, p. 163)

From a psychological perspective, the search for "solutions" implies problems rather than neurological difference. Through empirical analysis, scientists seek out answers for solving the riddle, and thus Theory of Mind is an ascription of a problematic upon the autistic person, thus injuring his/her subjecthood. Their thesis is that autism and any other disability are inherently a part of the world. They state, "We (you and I) are tied to each other by way of our communication, a mode of relation that is, also and always, coming undone, incomplete, partial, due to a fundamental excess inherent in every moment of contact” (McGuire \& Michalko, 2011, p. 164). It comes into being in the social spaces between people. Autism "derives its meaning in and through the relationships that connect us, in and through the lines of relation that bind you and I together as a 'we'” (McGuire \& Michalko, 2011, p. 164). Autism is a social phenomenon because it has social effects. It is named by people in the social world and is lived by people in the social world. Theory of Mind on the other hand reduces autism to a modular brain function and a way of being in the world.

If Theory of Mind is essential to subjecthood and autistics possess a non-existent or damaged Theory of Mind, then it follows that autistics are alien. McGuire and Michalko are concerned about the impact on humanity and communication if these theories are accepted. They state, "Communication is revealed as an act of negotiation between distance and proximity, a movement between these two possibilities” (McGuire \& Michalko, 2011, p. 175). They both believe that Theory of Mind permits no negotiation because it determines how communication takes place, thus limiting its possibilities. In doing so, they argue, Theory of Mind limits "authentic" communication, which is defined by the mutual collaboration using speech and language among people. However, Theory of Mind has been significant in an unanticipated way: it has engaged scholars from education, philosophy and psychology, such as Dinishak and Akhtar, who problematize the metaphor of mindblindness. They argue that mindblindness obscures the nature of communication, creates negative connotations, influences neurotypical ascriptions of autistic behavior, and blurs the line between deficit and 
difference (Dinishak \& Akhtar, 2013 p. 111). Mindblindness has indeed been instrumental in creating the ground for interdisciplinary discussions critiquing the basis of the metaphor as well as providing alternative explanations to autistics thinking and being in the world.

The rhetorical trope of metaphor is at the center of the discussion. Metaphor acts as a "standing-in" of the conception of being in the description by psychologists in the above example. This is an interesting idea because autism is seen as metaphorical "lack" in neuroscience research. The objecting scholars from the field of social science turn that idea on its head and apply the metaphor of the autistic as puzzle or autistic as alien to critique the neuroscience research. Given the fact that Baron-Cohen's research is "theory," this has invited dialogue from other quarters to re-theorize the nature of autism and autistic identity.

\section{Humanities Critiques of Mindblindness}

Humanities scholars have actively advocated for and rethought their position on the mindblindness metaphor. As such, they also contribute, in an interdisciplinary fashion, to how we look at literature and use neuroscience to do so. One such scholar is Lisa Zunshine, whose article, "Theory of Mind and Experimental Representations of Fictional Consciousness," integrates cognitive literary theory by using Theory of Mind as its principal ground. Zunshine utilizes Woolf's text Mrs. Dalloway, where Peter Walsh is trembling upon seeing Clarissa. Zunshine asks the rhetorical question: how do we know that his "trembling" is to be accounted for by his excitement at seeing his Clarissa again after all these years and not, for instance, by his progressing Parkinson's disease? (2003, p. 193). Zunshine's point is that the narrator (or author) tells us so; we must interpret Peter's emotions to be the cause. This aspect of our interpretation is based on the Theory of Mind. We attribute mental states to characters in fiction as well as to real characters (men and women) in life, according to Zunshine.

Zunshine comments on autism as a potential rift in the literary examination. She states, "Today, however, this conversation can and must go on because recent research in cognitive psychology and anthropology has shown that not every reader can learn that the default meaning of a character's behavior lies with the character's mental state" (2003, p. 194). Of course, the individual she is referring to, one who has problems with fiction reading, is the autistic person. This statement has a great deal of impact from two different standpoints: first, from the identity of the autistic person and secondly, from the perspective of interdisciplinarity (utilizing science for literary purposes in this respect).

Zunshine makes some fundamental assumptions in her initial work. The first is that literary characters are the same as real people with respect to mindreading. She analogizes the character in fiction with a real person. She states:

Our ability to interpret the behavior of real-life people — and by extension (her emphasis), of literary characters — in terms of their underlying states of mind seems to be such an integral part of being human that we could be understandably reluctant to dignify it with a fancy term and elevate it into a separate object of study. (Zunshine, 2003, p. 195)

These words are almost identical to Baron-Cohen's words, where he discusses the automaticity of neurotypicals attributing mental states to others. However, this means that this simple task, when it cannot be handled by someone, makes them, as Baron Cohen says, "alien.” Zunshine argues that normal people have cognitive endowments that reach to an effective reading of fiction, while autistics are challenged in these areas:

...by studying autism and a related constellation of cognitive deficits (such as Asperger syndrome), cognitive scientists and philosophers of mind began to appreciate our mind-reading ability as a special cognitive endowment, 
structuring in suggestive ways our everyday communication and cultural representations. (Zunshine, 2014, p. 195)

She sets up an us versus them dichotomy by using the word "our" mindreading ability (Zunshine as neurotypical). Zunshine uses brain research and extends that discussion into the realm of literary interpretation, specifically in the area of narratology.

Zunshine does acknowledge that, “The nuances of each person's mindreading profile are unique to that person, just as, for example, we all have the capacity to develop memories, although each person's memories are unique” (2014, p. 209). This opens the door for alternative explanations of autistic abilities to mindread. Zunshine seems to be suggesting that despite fundamental limitations in mindreading, some autistics may be able to do so.

Zunshine has since reworked her position in the face of interdisciplinary challenges from psychologists and sociologists. Zunshine and Ralph Savarese’s article, “The Critic as Neurocosmopolite; Or, What Cognitive Approaches to Literature Can Learn from Disability Studies,” stands as an example of the influence of disability studies research on the mindblindness dialogue. The rhetorical arrangement of the article is in the form of a dialogue, which speaks to the dialogic nature of the interaction between Zunshine, a cognitive literary theorist, and Ralph Savarese, a postcolonial theorist who applies that type of reading to autism and disability studies. This is a far different rhetorical arrangement than Zunshine's previous texts which co-opt the highly empiricist language of Baron Cohen's mindblindness theory for literary ends.

Zunshine moves away from her previous monologic stance towards autistic identity and cites scholarship on Spivak’s postcolonial ideology naming the autistic subject as the subaltern (2014, p. 18). She allows Savarese to speak from the position of disability studies scholar and parent to an autistic son. He argues that medical patients are like colonized peoples, their bodies and minds have been conquered and "in its place, an official narrative, in something like a foreign language, has prevailed, leaving patients feeling both alienated and disempowered" (2014, p. 18). He later says that "if one actually listens to autistics, one hears a different story" (2014, p. 19). Savarese's coinage of the term neurocosmopolitanism speaks to the idea of this fundamental dialogue between neuroatypical and neurotypical individuals co-creating knowledge of difference and collaboration.

Savarese utilizes neuroscience to explain the rhetorical nature of autism. He explains the thinking process of an autistic author named Tito Mukhopadhyay, whose mindblindness leads him to utilize rhetorical figuration in order to identify people he has met (2014, p. 19). He remembers people by linking their faces to idiosyncratic symbols. In other words, Mukhopadhyay uses metaphor for remembering people's faces. Savarese doesn't reject the mindblindness theory totally; he tells the story of mindblindness from a completely different perspective. The idea that the need to circumvent biological difference ironically facilitates the production of figurative language in an autistic person is fascinating. Cognitive scientists do not spend much time on autistic subjects. In addition, their tests, such as the false belief test, don't allow for autistic dialogue. Disability studies contribute to widening the view of autistic performance because it allows the autistic person to speak, something empirical science frowns upon.

Zunshine alters her earlier views on the application of mindblindness to literary texts. She takes into account the interdisciplinary contestation engendered by her earlier work and adjusts her views accordingly. She states that,

In exploring how theory of mind structures cultural representations, one should not lose sight of the dark side of mindreading. Because mindreading is not telepathy but merely a far-from-perfect adaptation (they might as well have 
called it mind misreading), more often than not it actually limits our perception and interpretation and lures us into insidious cognitive traps. (2012, p. 21)

The "our" in this passage is the neurotypical person, and the process of mindreading, which in her earlier work was so vital to her theory, she now believes creates cognitive biases in the general public which are "deeply ironic and tragic” (2012, p. 21). Zunshine's new belief is that failure to acknowledge autistic mindblindness as a metaphor feeds essentialist thinking (2012, p. 24). She states, "Ascribing an impoverished mental state to a person is a step necessary for imagining him or her as the Other” (2012, p. 24).

Zunshine has moved far away from her original work on mindblindness as the calling card for autism. While she does not deny the scientific origins and evidence of the theory, she looks at mindblindness from the multiple perspectives of the autist, as well as from scholars moving in social constructionist perspectives. It appears as if the rhetoric of social science, with its meaning-making apparatus and focus on the individual subject, has been highly persuasive with respect to her position on the theory. In addition, the rhetoric of disability studies has altered her views on the rhetoric of mindblindness. Zunshine's more expansive position with respect to mindblindness now encompasses the individual autistic as well as the theory itself. Again, rhetorical convergence in the form of metaphor has allowed for multiple perspectives representing autism in multiple forms. It has "greased the skids" and allowed for a different definition of mindblindness than previously rendered only by the neuroscientist.

Autism has proliferated as a diagnosis over the last twenty years. Because of its rise, there is increased interest in defining and discussing autism. Simon Baron-Cohen formulated mindblindness as an explanatory rhetoric for the deficits demonstrated in false belief tests on autistic children. However, despite the deficit metaphors originating in cognitivist explanations, scholars from other disciplines have utilized rhetorical tropes to re-define autism. Both social scientists and humanities scholars interested in aspects of communication have displayed the flexibility of rhetoric by teasing out different meanings of mimesis, metaphor, and identity. Rather than mindblindness theory shackling autistic identity in empiricist ways, different applications of rhetorical critique have "greased the skids," making possible a more thorough examination of the validity of mindblindness and what it means for autistic identity.

\section{Conclusion}

The achievement of this paper is to indicate that mindblindness discussion has moved out of the realm of science and into the realms of social science and the humanities. As such, it has been a productive concept in the formulation of discussions around autism and disability generally. The major contribution here is that mindblindness, despite being a deficit term in the debates over autism, has ultimately been useful as a launching point for interdisciplinary discussions, leading to mutual benefit crossing borders.

\section{References}

Aminoff, B. Z. (2015). On mechanisms of human behavior: The “mind blindness phenomenon” in philosophy, religion, science, and medicine. Philosophy Study, 5(3), 157-167.

Augsburg, T. (2006). Becoming interdisciplinary: An introduction to interdisciplinary studies. Dubuque, IA: Kendall/Hunt Pub. Baron-Cohen, S. (1995). Mindblindness: An essay on autism and theory of mind. Cambridge, MA: MIT.

Baron-Cohen, S. (2008). Autism and Asperger syndrome: The facts. Oxford: Oxford University Press.

Baron-Cohen, S., Leslie, A. M., \& Frith, U. (1985). Does the autistic child have a "theory of mind”?. Cognition, 21(1), 37-46. 
Baron-Cohen, S., Tager-Flusberg, H., \& Cohen, D. J. (1993). Understanding other minds: Perspectives from autism. Oxford: Oxford University Press.

Bombaci, N. (2012). Performing mindblindness: Gertrude Stein’s autistic ethos of modernism. Journal of Gender Studies, 21(2), 133-150.

Conson, M., Elisabetta, M., Dalila, E., Dario, G., Nicoletta, M., Angelo, M., \& Alessandro, F. (2015). "Put myself into your place”: Embodied simulation and perspective taking in autism spectrum disorders. Autism Research, 100-120.

Diagnostic and Statistical Manual of Mental Disorders: DSM-IV. (1994). Washington, D.C.: American Psychiatric Association.

Dinishak, J., \& Nameera, A. (2013). A critical examination of mindblindness as a metaphor for autism. Child Dev Perspect Child Development Perspectives, 7(2), 110-114.

Foss, S. K. (1989). Rhetorical criticism: Exploration \& practice. Prospect Heights, IL: Waveland.

Franklin, E., \& Brendan, H. (2010). The half-life of planets: A novel. New York: Hyperion.

Frith, C. D., \& Uta, F. (2012). Mechanisms of social cognition. Mechanisms of Social Cognition, 63, 287-313.

Genova, L. (2012). Love Anthony: A novel. New York: Gallery.

Gipps, R. (2004). Autism and intersubjectivity: Beyond cognitivism and the theory of mind. Philosophy, Psychiatry, \& Psychology, 11(3), 195-198.

Gray, J. (2004). Men are from Mars, women are from Venus: The classic guide to understanding the opposite sex. New York: HarperCollins.

Gunn, G. (2010). Being interdisciplinary. A Primer Interdisciplinary Environmental Studies, 142-151.

Hamilton, J. (9 July 2006). Autism reveals social roots of language. Google Scholar.

Jordan, R. (1999). Autistic spectrum disorders: An introductory handbook for practitioners. London: David Fulton.

Kerr, C. E. (2008). Dualism redux in recent neuroscience: “Theory of mind” and “embodied simulation” hypotheses in light of historical debates about perception, cognition, and mind. Review of General Psychology, 12(2): 205-214.

Klein, J. T. (1990). Interdisciplinarity: History, theory, and practice. Detroit: Wayne State University Press.

McGuire, A. E., \& Rod, M. (2011). Minds between us: Autism, mindblindness and the uncertainty of communication. Educational Philosophy and Theory, 43(2), 162-176.

McKerrow, R. E. (2009). Ideological rhetoric. In S. W. Littlejohn and K. A. Foss (Eds.), Encyclopedia of communication theory (pp. 497-498). Thousand Oaks, CA: SAGE Publications, Inc.

Moon, E. (2003). The speed of dark. New York: Ballantine.

Perner, J., Frith, U., Leslie, A., \& Leekam, S. (1989). Exploration of the Autistic child's theory of mind: Knowledge, belief, and communication. Child Development, 60, 689-700.

Porayska-Pomsta, K., Frauenberger, C., Pain, H., Rajendran, G., Smith, T., Menzies, R., ... Lemon, O. (2011). Developing technology for autism: An interdisciplinary approach. Pers Ubiquit Comput Personal and Ubiquitous Computing, 16(2), 117-127.

Röhricht, F. et al. (2014). Embodied cognition and body psychotherapy: The construction of new therapeutic environments. E-Journal of Applied Psychology, 10(1), 11-20.

Russell, A. J. et al. (2005). Obsessions and compulsions in Asperger syndrome and high-functioning autism. British Journal of Psychiatry, 186(6), 525-528.

Savarese, R. J., \& Zunshine, L. (2014). The critic as neurocosmopolite; Or, what cognitive approaches to literature can learn from disability studies: Lisa Zunshine in conversation with Ralph James Savarese. Narrative, 22(1), 17-44.

Stork, F. X. (2009). Marcelo in the real world. New York: Arthur A. Levine.

Zunshine, L. (2003). Theory of mind and experimental representations of fictional consciousness. Narrative, 11(3), $270-291$.

Zunshine, L. (2006). Why we read fiction: Theory of mind and the novel. Columbus: Ohio State University Press.

Zunshine, L. (2008). Theory of mind and fictions of embodied transparency. Narrative, 16(1), 65-92.

Zunshine, L. (2012). Getting inside your head: What cognitive science can tell us about popular culture. Baltimore: Johns Hopkins University Press. 